University of Nebraska - Lincoln

DigitalCommons@University of Nebraska - Lincoln

2010

\title{
Understanding Attitudes Toward People With Down Syndrome
}

Jill E. Pace

Centers for Disease Control and Prevention, jpace@usaid.gov

Mikyong Shin

Centers for Disease Control and Prevention, mshin@cdc.gov

Sonja A. Rasmussen

Centers for Disease Control and Prevention, skr9@cdc.gov

Follow this and additional works at: https://digitalcommons.unl.edu/publichealthresources

Part of the Public Health Commons

Pace, Jill E.; Shin, Mikyong; and Rasmussen, Sonja A., "Understanding Attitudes Toward People With Down Syndrome" (2010). Public Health Resources. 265.

https://digitalcommons.unl.edu/publichealthresources/265

This Article is brought to you for free and open access by the Public Health Resources at DigitalCommons@University of Nebraska - Lincoln. It has been accepted for inclusion in Public Health Resources by an authorized administrator of DigitalCommons@University of Nebraska - Lincoln. 


\title{
Understanding Attitudes Toward People With Down Syndrome
}

\author{
Jill E. Pace, ${ }^{1}$ Mikyong Shin, ${ }^{1,2}$ and Sonja A. Rasmussen ${ }^{1 *}$ \\ ${ }^{1}$ National Center on Birth Defects and Developmental Disabilities, Centers for Disease Control and Prevention, Atlanta, Georgia \\ ${ }^{2}$ RTI International, Atlanta, Georgia
}

Received 31 December 2009; Accepted 16 June 2010

Understanding attitudes of the public toward people with Down syndrome is important because negative attitudes might create barriers to social integration, which can affect their success and quality of life. We used data from two 2008 U.S. surveys (HealthStyles $\subseteq$ survey of adults 18 years or older and YouthStyles $\odot$ survey of youth ages 9-18) that asked about attitudes toward people with Down syndrome, including attitudes toward educational and occupational inclusion and toward willingness to interact with people with Down syndrome. Results showed that many adults continue to hold negative attitudes toward people with Down syndrome: A quarter of respondents agreed that students with Down syndrome should go to special schools, nearly $30 \%$ agreed that including students with Down syndrome in typical educational settings is distracting, and $18 \%$ agreed that persons with Down syndrome in the workplace increase the chance for accidents. Negative attitudes were also held by many youth: $30 \%$ agreed that students with Down syndrome should go to separate schools, $27 \%$ were not willing to work with a student with Down syndrome on a class project, and nearly $40 \%$ indicated they would not be willing to spend time with a student with Down syndrome outside of school. Among both adult and youth, female sex and respondents with previous relationships with people with Down syndrome were consistently associated with more positive attitudes. These results may be helpful in the development of educational materials about Down syndrome and in guiding policies on educational and occupational inclusion. Published 2010 Wiley-Liss, Inc.

Key words: Down syndrome; attitudes; intellectual disabilities

\section{INTRODUCTION}

Down syndrome is the most commonly identified chromosomal abnormality causing intellectual disability in humans [Yang et al., 2002; Sherman et al., 2007]. The prevalence of Down syndrome is approximately 1 in 730 live births [Centers for Disease Control and Prevention, 2006]. Common health concerns of people with Down syndrome include cognitive impairment, hypotonia, congenital heart defects, and gastrointestinal defects [Korenberg et al., 1994; Frid et al., 1999; Rasmussen et al., 2008]. Attitudes of the general public toward people with Down syndrome are imperative to their successful integration into everyday life. Socially integrating
How to Cite this Article:

Pace JE, Shin M, Rasmussen SA. 2010.

Understanding attitudes toward people with Down syndrome.

Am J Med Genet Part A 152A:2185-2192.

a person with an intellectual disability depends not only on the person's abilities, but also on the attitudes of the general public toward people with intellectual disabilities [Abrams et al., 1990; Antonak and Livneh, 2000; Diamond and Kensinger, 2002]. In addition, understanding attitudes is important to guide the development of educational materials. Given recent changes in American College of Obstetricians and Gynecologists' recommendations to advise that pregnant women of all ages should be offered prenatal diagnostic tests to detect possible genetic abnormalities in their fetuses [ACOG, 2007] and potential future advances in prenatal diagnostic testing [Fan et al., 2008], additional educational materials will be needed for women considering these diagnostic tests as well as for those parents who learn that their fetus has been diagnosed with Down syndrome. An evaluation of attitudes of adults and youth toward people with Down syndrome is thus needed to inform policy, to design intervention programs and educational materials, and to evaluate professional training [Antonak and Livneh, 2000].

Previous research on attitudes toward people with intellectual disabilities focused on attitudes toward inclusive education and workplace environments and the effects of previous relationships with people with intellectual disabilities on those attitudes. Several studies showed positive attitudes toward inclusive education of

The findings and conclusions in this report are those of the authors and do not necessarily represent the official position of the Centers for Disease Control and Prevention.

${ }^{\star}$ Correspondence to:

Sonja A. Rasmussen, M.D., M.S., Centers for Disease Control and Prevention, MS E-86, 1600 Clifton Road NE, Atlanta, GA 30333.

E-mail: skr9@cdc.gov

Published online 18 August 2010 in Wiley Online Library

(wileyonlinelibrary.com)

DOI 10.1002/ajmg.a.33595 
people with intellectual disabilities [Guralnick et al., 1995; Hocutt, 1996; Kasari et al., 1999; Cooney et al., 2006], while others showed negative attitudes [Siperstein et al., 2003; Burke and Sutherland, 2004; Bhagat, 2007; Smith, 2007]. In studies on inclusive workplace environments, employers and employees expressed favorable attitudes toward employing people with intellectual disabilities [Levy et al., 1993; Unger, 2002]. Previous studies have demonstrated that people who have previous relationships and contact with people with an intellectual disability have more positive attitudes [Tripp et al., 1995; Maras and Brown, 1996; Unger, 2002].

Studies on youth show that children often have negative attitudes toward peers with intellectual disabilities [Nabors and Keyes, 1995; Nowicki, 2003]. However, research on factors associated with positive or negative attitudes toward peers with intellectual disabilities is inconsistent. Several studies have examined the effect of sex on attitudes toward peers with intellectual disabilities; some studies have shown that females have more positive attitudes toward peers with intellectual disabilities [Townsend et al., 1993; Nabors and Keyes, 1995; Tripp et al., 1995; Gash et al., 2000; Nowicki, 2003], while others showed no difference in attitudes by sex [Cohen and Lopatto, 1995; Tamm and Prellwitz, 2001]. Similarly, the research on age and its effect on attitudes toward peers with intellectual disabilities is inconsistent. Several studies reported that younger children have more positive attitudes toward peers with intellectual disabilities [Gash and Coffey, 1995], while others showed no significant differences in attitudes by age [Tamm and Prellwitz, 2001].

There are several gaps in the literature regarding attitudes toward people with intellectual disabilities. First, current research on attitudes toward people with intellectual disabilities is limited. Second, few studies have been conducted in the United States. Finally, we are not aware of any research studies in the past decade on attitudes of the U.S. public specifically toward people with Down syndrome. The purpose of this study is to understand more current attitudes of the general U.S. population (adults and youth) toward people with Down syndrome and to explore factors associated with these attitudes.

\section{MATERIALS AND METHODS Subjects}

This study is a cross-sectional design; data were collected from the HeathStyles(C) and YouthStyles $($ ) surveys, two questionnaires distributed by Porter Novelli and Synovate, Inc. The HealthStyles@ and YouthStyles( $\subset$ surveys are supplements of the ConsumerStyles $(\subset$ survey, a questionnaire sent to a stratified random sample of 20,000 people. The sample was stratified on region, household income, population density, age, and household size to create a nationally representative sample. The HealthStyles $\subset$ and YouthStyles(C) data were stratified and weighted to the 2007 Census Current Population Survey [Pollard, 2002]. The HealthStyles $\subset$ data were weighted on the five demographic variables of age, race and ethnicity, sex, household size, and income. YouthStyles@ data were weighted using the age and sex of child, household size, household income, age of the head of household, and race and ethnicity of the adult in the study. Participants were entered into a raffle for a first place prize of $\$ 1,000$ and 20 second place prizes of $\$ 50$. Personal identifiers were removed before data were received. Review by the CDC institutional review board was not necessary because researchers had no access to individually identifiable data.

\section{Questionnaire}

The 2008 HealthStyles $(\subset)$ and YouthStyles $@$ questionnaires had 207 and 57 questions, respectively, designed to collect basic demographic information as well as information related to health issues, attitudinal variables, and media preferences. Both surveys included four items specifically related to attitudes toward people with Down syndrome, which were adapted from previous surveys [Antonak and Livneh, 2000; Siperstein et al., 2003].

HealthStyles (C) respondents were instructed to choose one of five response choices on a Likert scale that accurately reflected their level of agreement with the corresponding statement or category. YouthStyles $@$ respondents were instructed to choose one of four response choices on a Likert scale that accurately reflected their level of agreement. The four items related to Down syndrome in the HealthStyles $($ ) questionnaire asked about attitudes toward people with Down syndrome in educational and workplace settings (Fig. 1). The four items related to Down syndrome in the YouthStyles (C) questionnaire asked about attitudes toward people with Down syndrome and inclusive education, and willingness to interact with people with Down syndrome inside and outside of the school setting (Fig. 1).

\section{Data Analysis}

For the HealthStyles $(C)$ data, independent variables analyzed as potentially associated with attitudes toward people with Down syndrome were age, sex, race and ethnicity, previous relationships with people with Down syndrome, education, employment status, geographic region, household size, and annual household income. The odds ratios for questions 1-3 compared the odds of "agree" with the odds of "disagree." Agreement consisted of the responses "agree" and "really agree," and disagreement consisted of the responses "disagree" and "really disagree" on a five-point Likert scale. Odds ratios for question 4 compared the odds of answering "They (people with Down syndrome) should not work" with the odds of answering "They (people with Down syndrome) should work."

For YouthStyles $(\subset)$ data, independent variables analyzed as potentially associated with attitudes toward Down syndrome were age, sex, previous relationships, geographic region, annual household income, and household size, For questions 1 and 2, odds ratios compared the odds of "agree" with the odds of "disagree." For questions 3 and 4, odds ratios compared the odds of "disagree" with the odds of "agree." Agreement consisted of the responses "sort of agree" and "really agree," and disagreement consisted of the responses "sort of disagree" and "really disagree" on a four-point Likert scale.

Logistic regression was used to estimate crude and adjusted odd ratios (aOR) with 95\% confidence intervals (CIs) between the variables listed previously and the attitudes toward people with Down syndrome. Data analysis was performed using SPSS version 17.0. 
A Reported attitudes toward people with Down syndrome, HealthStyles

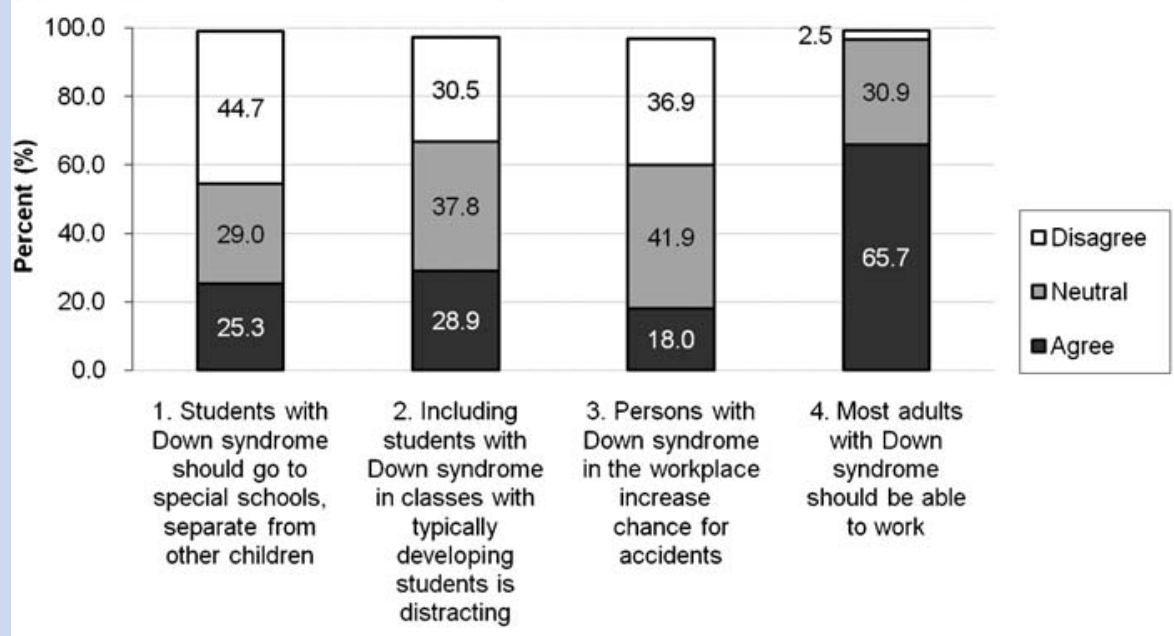

B Reported attitudes toward people with Down syndrome, YouthStyles

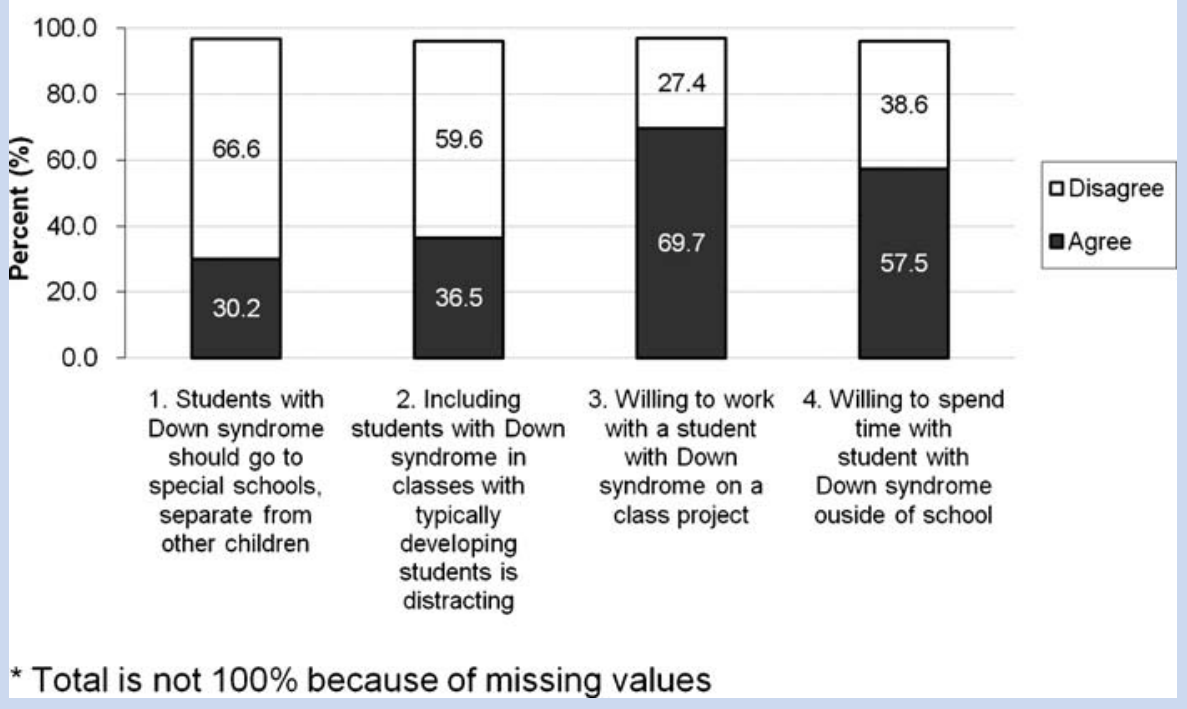

FIG. 1. Attitudes toward people with Down syndrome-United States-HealthStyles $\subset$ (A) and YouthStyles $\subset$ (B) - 2008.

\section{RESULTS}

A total of 7,000 HealthStyles (C) surveys and 2,605 YouthStyles@ surveys were sent to participants. Responses were received from 5,399 HealthStyles@ participants and 1,704 YouthStyles@ participants, yielding response rates of $77.1 \%$ and $65.4 \%$, respectively. Demographic characteristics of HealthStyles $@$ respondents and YouthStyles $\subset$ are presented in Table I. Among adult respondents, $34.4 \%$ stated they had a previous relationship with a person with Down syndrome. The categories of relationships on the HealthStyles@ questionnaire were child, sibling, other relative, family friend, and other. Among youth respondents, 32.7\% stated they had a previous relationship with a person with Down syndrome. The categories of relationships on the YouthStyles $\subset$ questionnaire were sibling, other relative, friend, classmate, and other.

\section{Attitudes Toward People With Down Syndrome}

Based on results of the HealthStyles survey (Fig. 1A), a significant proportion of adult respondents (25.3\%) agreed that students with Down syndrome should go to special schools and 28.9\% agreed that including students with Down syndrome in classes with typically developing students is distracting. Eighteen percent agreed that people with Down syndrome in the workplace increase the chance for accidents. However, most respondents $(65.7 \%)$ agreed with the statement that most adults with Down syndrome should be able to work and only $2.5 \%$ disagreed with this statement.

Based on results from the YouthStyles survey (Fig. 1B), $30.2 \%$ of youth respondents agreed that students with Down syndrome should go to special schools, separate from other 
TABLE I. Reported Demographic Characteristics, United States, HealthStyles $\odot$, and YouthStyles $\odot, 2008^{\text {a }}$

\begin{tabular}{|c|c|c|c|}
\hline $\begin{array}{l}\text { HealthStyles } @ \\
\text { characteristics }\end{array}$ & Frequency $n[\%]$ & $\begin{array}{l}\text { YouthStyles@ } \\
\text { characteristics }\end{array}$ & Frequency $n[\%]$ \\
\hline Age group & \multicolumn{2}{|r|}{ Age group } & \\
\hline $18-34$ & $1,652(30.6)$ & $9-13$ & 829 (48.7) \\
\hline $35-54$ & 2,090 (38.7) & \multirow[t]{2}{*}{$14-18$} & $875(51.3)$ \\
\hline $55+$ & $1,657(30.7)$ & & \\
\hline \multicolumn{2}{|l|}{ Sex } & \multicolumn{2}{|l|}{ Sex } \\
\hline Male & $2,613(48.4)$ & Male & $873(51.2)$ \\
\hline Female & $2,786(51.6)$ & Female & 831 (48.8) \\
\hline \multicolumn{2}{|l|}{ Household income } & \multicolumn{2}{|l|}{ Household income } \\
\hline$<\$ 32,500$ & $1,801(33.4)$ & $<\$ 32,500$ & $383(22.4)$ \\
\hline$\$ 32,500-74,999$ & $1,942(36.0)$ & $\$ 32,500-74,999$ & $642(37.7)$ \\
\hline$\geq \$ 75,000$ & $1,656(30.7)$ & $\geq \$ 75,000$ & 680 (39.9) \\
\hline \multicolumn{2}{|l|}{ Household size } & \multicolumn{2}{|l|}{ Household size } \\
\hline$\leq 2$ people & $3,249(60.2)$ & $\leq 3$ people & $566(33.2)$ \\
\hline \multirow{2}{*}{\multicolumn{2}{|c|}{ Geographic region ${ }^{\mathrm{b}}$}} & $\geq 4$ people & $1,138(66.8)$ \\
\hline & & \multicolumn{2}{|l|}{ Geographic region } \\
\hline Northeast & $1,035(19.2)$ & Northeast & $296(17.4)$ \\
\hline Midwest & $1,350(25.0)$ & Midwest & $452(26.5)$ \\
\hline West & $1,104(20.4)$ & West & 340 (19.9) \\
\hline South & $1,910(35.4)$ & South & $616(36.2)$ \\
\hline \multicolumn{2}{|l|}{ Previous relationships ${ }^{\mathrm{c}, \mathrm{d}}$} & \multicolumn{2}{|l|}{ Previous relationships } \\
\hline Yes & $1,855(34.4)$ & Yes & 557 (32.7) \\
\hline No & $3,418(63.3)$ & No & $1,046(61.4)$ \\
\hline Do not know what Down syndrome is & 103 (1.9) & Do not know what Down syndrome is & $89(5.2)$ \\
\hline \multicolumn{4}{|l|}{ Race and ethnicity } \\
\hline White & $3,682(68.2)$ & & \\
\hline Black & 637 (11.8) & & \\
\hline Hispanic & $718(13.3)$ & & \\
\hline Other & 362 (6.7) & & \\
\hline \multicolumn{4}{|l|}{ Education $^{d}$} \\
\hline Did not graduate high school & $344(6.4)$ & & \\
\hline High school graduate-4 years of college & $4,265(79.0)$ & & \\
\hline Post graduate school & 659 (12.2) & & \\
\hline \multicolumn{4}{|l|}{ Employment status ${ }^{\mathrm{d}, \mathrm{e}}$} \\
\hline Yes & $4,021(74.5)$ & & \\
\hline No & $1,254(23.2)$ & & \\
\hline Total $N[\%]$ & $5,399[100.0]$ & Total $\mathbf{N}[\%]$ & $1,704[100.0]$ \\
\hline \multicolumn{4}{|c|}{$\begin{array}{l}\text { aAll data were weighted and the resulting numbers were rounded to the nearest whole number. } \\
\text { 'The Northeast includes Connecticut, Maine, Massachusetts, New Hampshire, New Jersey, New York, Pennsylvania, Rhode Island, and Vermont. The Midwest includes Illinois, Indiana, lowa, } \\
\text { Kansas, Michigan, Minnesota, Missouri, Nebraska, North Dakota, Ohio, South Dakota, and Wisconsin. The South includes Alabama, Arkansas, Delaware, Florida, Georgia, Kentucky, Louisiana, } \\
\text { Maryland, Mississippi, North Carolina, Oklahoma, South Carolina, Tennessee, Texas, Virginia, Washington, DC, and West Virginia. The West includes Arizona, California, Colorado, Idaho, Montana, } \\
\text { Nevada, New Mexico, Oregon, Utah, Washington, and Wyoming. } \\
{ }^{\circ} \text { For HealthStyles } \odot \text {, previous relationship = child, sibling, other relative, family friend, and other; for YouthStyles } \odot \text {, previous relationship = sibling, other relative, friend, classmate, and other. } \\
{ }^{d} \text { Total is not } 100 \% \text { because of missing values. }\end{array}$} \\
\hline
\end{tabular}

children, and $36.5 \%$ of respondents agreed that including students with Down syndrome in classes with typically developing students is distracting. Over a quarter of youth respondents $(27.4 \%)$ were not willing to work with a student with Down syndrome on a class project, and the majority of youth respondents $(38.6 \%)$ stated they would be unwilling to spend time with a student with Down syndrome outside of school.

\section{Factors Associated With Attitudes Toward People With Down Syndrome}

Among both adult and youth respondents, females and those with previous relationships with people with Down syndrome were consistently more likely to have positive attitudes toward people with Down syndrome (Tables II and III). The age of adult respondents was not associated with attitudes toward people with 
TABLE II. Association of Attitudes Toward People With Down syndrome, Adjusted by All Other Factors, United States, HealthStyles $\left(2008^{a}\right.$

Adjusted odds ratios ${ }^{b}$

(95\% confidence interval)

Age group

$$
\begin{aligned}
& 18-34 \\
& 35-54 \\
& 55+
\end{aligned}
$$

Sex

Male

Female

Race and ethnicity

Black

Hispanic

Other

White

Previous relationships ${ }^{c}$

Yes

No

Education

Did not graduate high school

High school graduate-4 years college

Post graduate school

Employment status ${ }^{d}$

$$
\text { Yes }
$$

No

Household income

$<\$ 32,500$

$\$ 32,500-74,999$

$\geq \$ 75,000$

Household size

$\leq 2$ people

$\geq 3$ people

Region $^{\text {e }}$

Northeast

Midwest

West

South

\section{Students with \\ Down syndrome should go to \\ separate \\ schools [agree] \\ 2. Students with [agree]}

\section{Including people \\ with Down syndrome in the workplace \\ increases the \\ chance of \\ accidents [agree]}

$0.87(0.72-1.06)$

$0.72(0.59-0.87$ )

1.86 (1.61-2.15]

1.26 (1.01-1.58]

$1.09(0.87-1.35)$

1.65 (1.22-2.23]

$0.80[0.69-0.92]$

2.99 [2.12-4.22]

1.52 (1.22-1.90)

$0.76(0.63-0.91]$

$0.93(0.75-1.15)$

$0.90(0.71-1.14)$ Referent

0.80 (0.64-1.01)

3.28 (1.84-5.85]

$0.96(0.51-1.81)$

3.14 [2.04-4.81] Referent
$0.55(0.43-0.70) \quad 1.01(0.76-1.32)$
$0.99(0.78-1.24) \quad 1.14(0.88-1.46)$
$1.26(0.91-1.76)$
Referent
$2.06(1.46-2.90)$

$1.60(0.84-3.05)$

$1.02(0.57-1.81)$

$0.74(0.31-1.73)$

$0.74[0.64-0.86] \quad 0.69[0.58-0.81]$ Referent
$2.67(1.84-3.89) \quad 3.19(2.13-4.79)$
1.54 [1.23-1.93] 1.62 (1.23-2.13] Referent
$0.74(0.61-0.90) \quad 0.87(0.70-1.09)$ Referent

$0.88(0.72-1.07)$
$0.90(0.76-1.08)$

$0.92(0.75-1.13)$
$0.95(0.90-1.14)$

$1.14(0.91-1.44)$ Referent

0.86 (0.70-1.05)

1.34 [1.15-1.56]

$1.15(0.98-1.35)$

0.99 (0.83-1.18) Referent

$1.13(0.93-1.38)$
$0.88(0.73-1.06)$
$\mathbf{0 . 7 5}(\mathbf{0 . 6 1 - 0 . 9 2})$
$0.67(0.39-1.18)$

$0.80(0.49-1.30)$

$16.98(7.16-40.30)$

2.14 (0.98-4.67)

1.09 (0.61-1.95)

$1.22(0.81-1.85)$

$0.66(0.36-1.19)$

$1.11(0.68-1.81)$

$1.03(0.59-1.81)$ $\begin{array}{ll}0.82(0.66-1.00) & 0.86(0.68-1.10) \\ \mathbf{0 . 8 2}(\mathbf{0 . 6 7}-\mathbf{0 . 9 9}) & 0.85(0.68-1.06) \\ \mathbf{0 . 7 9}(\mathbf{0 . 6 4}-\mathbf{0 . 9 8}) & 0.93(0.74-1.17)\end{array}$ Referent

Statistically significant findings $(P<0.05)$ are in bold typeface.

aThe questions "Students with Down syndrome should go to special schools, separate from other children," "Including students with Down syndrome in classes with typically developing students is distracting," and "Including people with Down syndrome in the workplace increases the chance of accidents" and "Adults with Down syndrome should not work" all compare the odds of "agreement" to the odds of "disagreement."

bach model adjusted for all other variables.

${ }^{\mathrm{c}}$ For HealthStyles $\odot$, previous relationship $=$ child, sibling, other relative, family friend, and other.

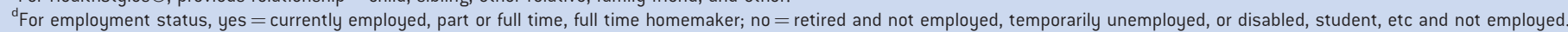

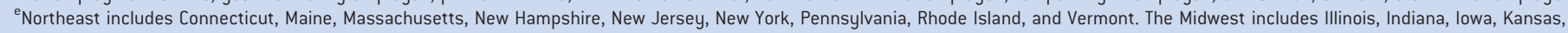
Michigan, Minnesota, Missouri, Nebraska, North Dakota, Ohio, South Dakota, and Wisconsin. The South includes Alabama, Arkansas, Delaware, Florida, Georgia, Kentucky, Louisiana, Maryland, Mississippi, North Carolina, Oklahoma, South Carolina, Tennessee, Texas, Virginia, Washington, DC, and West Virginia. The West includes Arizona, California, Colorado, Idaho, Montana, Nevada, New Mexico, Oregon, Utah, Washington, and Wyoming.

Down syndrome, except that younger adults showed substantially more negative attitudes toward people with Down syndrome in the workplace $(\mathrm{aOR}=3.28,95 \%$ CI $1.84-5.85)$ (Table II). Among adults, a higher level of education resulted in more positive attitudes toward people with Down syndrome for all questions. The asso- ciation between education and attitudes was particularly strong for attitudes toward people with Down syndrome in the workplace: Adults with less than a high school education were nearly 17 times more likely to agree that adults with Down syndrome should not work than persons with post-graduate school education 
TABLE III. Association of Attitudes Toward People With Down syndrome, Adjusted by All Other Factors, United States, YouthStyles@, 2008 ${ }^{\mathrm{a}}$

\begin{tabular}{|c|c|c|c|c|}
\hline & $\begin{array}{l}\text { 1. Students with } \\
\text { Down syndrome } \\
\text { should go to } \\
\text { separate schools } \\
\text { [agree] }\end{array}$ & $\begin{array}{l}\text { 2. Students with } \\
\text { Down syndrome } \\
\text { are distracting } \\
\text { [agree] }\end{array}$ & $\begin{array}{l}\text { 3. Willing to work with } \\
\text { a student with Down } \\
\text { syndrome on } \\
\text { class project } \\
\text { [disagree] }\end{array}$ & $\begin{array}{l}\text { 4. Willing to } \\
\text { spend time with a } \\
\text { student with Down } \\
\text { syndrome outside of } \\
\text { school (disagree) }\end{array}$ \\
\hline \multicolumn{5}{|l|}{$\begin{array}{l}\text { Adjusted odds ratios }{ }^{\mathrm{b}} \\
\text { (95\% confidence interval] } \\
\text { Age (years) }\end{array}$} \\
\hline $\begin{array}{l}9-13 \\
14-18\end{array}$ & \multicolumn{4}{|c|}{ Referent } \\
\hline \multicolumn{5}{|l|}{ Sex } \\
\hline $\begin{array}{l}\text { Male } \\
\text { Female }\end{array}$ & & \\
\hline \multicolumn{5}{|l|}{ Previous relationships ${ }^{c}$} \\
\hline Yes & $0.69[0.54-0.87)$ & $0.75(0.60-0.93)$ & $0.59(0.46-0.76)$ & $0.61(0.49-0.76)$ \\
\hline $\begin{array}{l}\text { Do not know what Down syndrome is } \\
\text { No }\end{array}$ & & \\
\hline \multicolumn{5}{|l|}{ Region $^{d}$} \\
\hline Northeast & $1.05(0.77-1.43)$ & $0.76(0.56-1.03)$ & $1.41[1.03-1.94]$ & $1.30(0.97-1.75)$ \\
\hline Midwest & $0.99(0.75-1.29)$ & 0.79 (0.61-1.02) & $1.15(0.86-1.52)$ & $1.25(0.96-1.62)$ \\
\hline West & $0.82(0.60-1.10)$ & $0.79(0.60-1.06)$ & $1.23(0.90-1.67)$ & $1.39(1.05-1.85)$ \\
\hline South & \multicolumn{4}{|c|}{ Referent } \\
\hline \multicolumn{5}{|l|}{ Household income } \\
\hline$<\$ 32,500$ & $0.84(0.63-1.12)$ & $0.56(0.42-0.74)$ & $0.94(0.70-1.26)$ & $0.92(0.70-1.21)$ \\
\hline$\$ 32,500-74,999$ & \multirow{2}{*}{\multicolumn{4}{|c|}{ Referent }} \\
\hline$\geq \$ 75,000$ & & & & \\
\hline \multicolumn{5}{|l|}{ Household size } \\
\hline $\begin{array}{l}\leq 3 \text { people } \\
\geq 4 \text { people }\end{array}$ & $1.04(0.83-1.31)$ & $1.04(0.83-1.29)$ & $\begin{array}{l}1.32[1.04-1.66] \\
\text { Referent }\end{array}$ & $1.23(0.99-1.52)$ \\
\hline \multicolumn{5}{|c|}{ 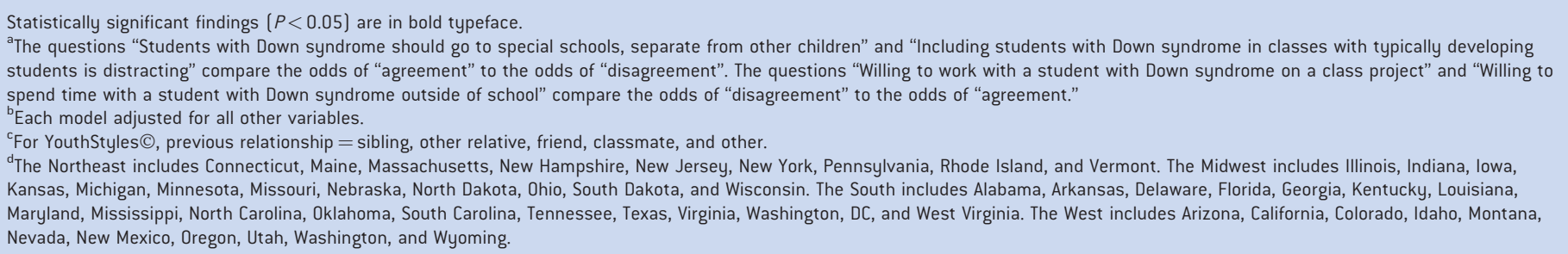 } \\
\hline
\end{tabular}

$(\mathrm{aOR}=16.98,95 \%$ CI 7.16-40.30) (Table II). Other factors including race-ethnicity, employment status, household income and size, and geographic region were not consistently associated with attitudes toward people with Down syndrome among adult respondents (Table II). Among youth respondents, factors including age, geographic region, household income, and household size were not consistently associated with attitudes toward people with Down syndrome (Table III).

\section{DISCUSSION}

Results from the HealthStyles $₫$ and YouthStyles $\odot$ respondents show that the U.S. general public continue to hold negative attitudes toward people with Down syndrome and their inclusion in both school and work environments. Among HealthStyles ()$^{\circ}$ respondents, the factors most strongly associated with positive attitudes toward people with Down syndrome were female sex, previous relationships with people with Down syndrome, and higher education. Among Youthstyles $\subseteq$ respondents, female sex and previous relationships with people with Down syndrome were most strongly associated with positive attitudes toward people with Down syndrome.

The HealthStyles $\Subset$ and Youthstyles $\odot$ results from this study support previous findings, which showed that people who had previous relationships with people with Down syndrome were more positive toward them [Tripp et al., 1995; Maras and Brown, 1996; Unger, 2002]. In a study by Tripp et al. [1995], the authors tested the effects of contact with children with disabilities, both physical and intellectual, and how this contact affected attitudes of youth. Results showed that students who were involved in integrated education programs had significantly better attitudes toward peers with intellectual disabilities than did students in 
segregated education programs. Our findings are consistent with the results of a study by Unger [2002], which revealed that people who had previous experiences with people with intellectual disabilities were more likely to have positive attitudes toward their inclusion in the workplace. Additional research studies showed that parents of children without intellectual disabilities were more likely to endorse inclusive education if they had previous experiences with people with intellectual disabilities; the quality of the previous experiences with people with intellectual disabilities was more important than the quantity of experiences with this population [Green and Stoneman, 1989].

Although previous research on youth attitudes toward people with intellectual disabilities has been inconsistent, several studies have stated that female children are more likely than male children to react positively when discussing children with intellectual disabilities [Townsend et al., 1993; Nabors and Keyes, 1995; Tripp et al., 1995; Gash et al., 2000; Nowicki, 2003]. Results from the YouthStyles @ survey are similar to these past results.

There are several limitations of this study. First, the HealthStyles@ and YouthStyles@ surveys are subject to selection bias because the survey populations are not randomly selected samples of the U.S. population. The populations are from a cohort of people who have agreed to participate in market research. Although the data were weighted to more accurately reflect the U.S. population, the results from this survey may not be comparable to the general population. Additionally, although the response rates for the HealthStyles $\subseteq$ and YouthStyles@ surveys were good, at $77.1 \%$ and $65.4 \%$, respectively, respondents were likely to have differed from non-respondents, thus, limiting the generalizability of the study. Respondents were more likely to be literate and English-speaking, given that the survey is written and only available in English; they were also more likely to be interested in health behaviors, the focus of the survey. However, a previous study showed that responses to questions from the HealthStyles@ survey were comparable to responses to similar questions obtained from random sampled survey data [Pollard, 2002]. Due to the sensitive nature of the topic, social desirability bias in the reporting may be a factor. We also note that this study was limited by its cross-sectional nature. Further study is needed to better understand the reliability and validity of the study questions.

The purpose of this study was to understand the attitudes of adults and youth toward people with Down syndrome and to understand factors that affect these attitudes. The public health implications of this research relate to both education and policy. First, results of this study can be used to develop educational materials for various audiences. For example, understanding attitudes of the general public toward people with Down syndrome is important to guide the development of educational materials for parents who are considering prenatal diagnostic testing or who have recently received a diagnosis of Down syndrome in their fetus or newborn infant. The results of this study may also be used to focus interventions to increase positive attitudes toward people with Down syndrome. For example, the results of our study revealed that males and those with less education have more negative attitudes toward people with Down syndrome. These results may inform an intervention targeting specific demographic groups to create more positive attitudes toward people with Down syndrome.
This study has important policy implications. The results of this study can be used to advocate for the greater inclusion of people with Down syndrome in education and work settings. Consistent with several previous studies, the results of our study show that people who have previous relationships with people with Down syndrome have more positive attitudes toward others with Down syndrome. These results can be used to influence educational policy and inform efforts for inclusion or integration of children with intellectual disabilities into schools and other settings, as well as to increase inclusion or participation in occupational environments. Programs that would increase inclusion could be a mentoring or buddy program in educational settings or work training program in occupational settings. This study provides evidence for the value of increasing the interaction between the general public and people with Down syndrome and other intellectual disabilities.

Future research should attempt to understand why certain factors are associated with positive or negative attitudes toward people with Down syndrome. In addition, future studies should examine other factors that might affect attitudes toward people with Down syndrome and examine in more detail how the type, quantity, and quality of previous relationships shape attitudes. Qualitative research studies, such as focus groups and in-depth interviews, might help to further examine attitudes toward people with Down syndrome and other intellectual disabilities.

\section{ACKNOWLEDGMENTS}

We thank Porter Novelli for the use of the HealthStyles@ and YouthStyles $@$ questionnaires. We thank Mr. Bill Pollard and Ms. Martha Alexander for their help with the HealthStyles $\subset$ and YouthStyles $@$ questionnaires. We also thank Ms. Patricia E. Bauer for helpful discussions on this topic.

\section{REFERENCES}

Abrams D, Jackson D, St. Claire L. 1990. Social identity and the handicapping functions of stereotypes: Children's understanding of mental and physical handicap. Hum Relat 43:1085-1098.

Antonak R, Livneh H. 2000. Measurement of attitudes towards persons with disabilities. Disabil Rehabil 22:211-224.

Bhagat F. 2007. Exploring inclusion and challenging policy in mainstream education. Br J Nurs 16:1354-1359.

Burke K, Sutherland C. 2004. Attitudes towards inclusion: Knowledge vs. experience. Education 125:163-172.

Centers for Disease Control and Prevention. 2006. Improved national prevalence estimates for 18 selected major birth defects, United States, 1999-2001. MMWR Morb Mortal Wkly Rep 54:1301-1305.

Cohen TL, Lopatto DE. 1995. Preschool children's comprehension of the world "handicapped." Percept Mot Skills. 81:747-750.

Cooney G, Jahoda A, Gumley A, Knott F. 2006. Young people with intellectual disabilities attending mainstream and segregated schooling: Perceived stigma, social comparison and future aspirations. J Intellect Disabil Res 50:432-444.

Diamond KE, Kensinger KR. 2002. Vignettes from Sesame Street: Preschooler's ideas about children with Down syndrome and physical disability. Early Educ Dev 13:409-422. 
Fan HC, Blumenfeld YJ, Chitkara U, Hudgins L, Quake SR. 2008. Noninvasive diagnosis of fetal aneuploidy by shotgun sequencing DNA from maternal blood. Proc Natl Acad Sci USA 105:16266-16271.

Frid C, Drott P, Lundell B, Rasmussen F, Annerne G. 1999. Mortality in Down's syndrome in relation to congenital malformations. J Intellect Disabil Res 43:234-241.

Gash H, Coffey D. 1995. Influences on attitudes towards children with mental handicap. Eur J Spec Needs Educ 10:1-16.

Gash H, Gonzales SG, Pires M, Rault C. 2000. Attitudes toward Down syndrome: A national comparative study: France, Ireland, Portugal, and Spain. Irish J Psychol 21:203-214.

Green AL, Stoneman Z. 1989. Attitudes of mothers and fathers of nonhandicapped children. J Early Intervent 13:292-304.

Guralnick MJ, Connor RT, Hammond M. 1995. Parent perspectives of peer relationships and friendships in integrated and specialized programs. Am J Ment Retard 99:457-476.

Hocutt AM. 1996. Effectiveness of special education: Is placement the critical factor? Future Child 6:77-102.

Kasari C, Freeman SFN, Bauminger N, Alkin MC. 1999. Parental perspectives on inclusion: Effects of autism and Down syndrome. J Autism Dev Disord 29:297-305.

Korenberg JR, Chen XN, Schipper R, Sun Z, Gonski R, Gerwehr S, Carpenter N, Daumer C, Dignan P, Disteche C. 1994. Down syndrome phenotypes: The consequences of chromosomal imbalance. Proc Natl Acad Sci USA 91:4997-5001.

Levy JJ, Rimmerman A, Levy PH. 1993. Determinants of attitudes of New York State employers towards the employment of persons with severe handicaps. J Rehabil 59:49-54.

Maras P, Brown R. 1996. Effects of contact on children's attitudes toward disabilities: A longitudinal study. J Appl Soc Psychol 26:2113-2134.

Nabors L, Keyes L. 1995. Preschoolers' reasons for accepting peers with and without disabilities. J Dev Phys Disabil 7:335-355.
Nowicki EA. 2003. A meta-analysis of the social competence of children with learning disabilities compared to classmates of low and average to high achievement. Learn Disability Q 26:171-188.

Pollard WE. 2002. Use of consumer panel survey data for public health communication planning: An evaluation survey results. In Proceedings of the Health Policy Statistics Section, American Statistical Association: 2120-2124.

Rasmussen SA, Whitehead N, Collier SA, Frias JL. 2008. Setting a public health research agenda for Down syndrome: Summary of a meeting sponsored by the Centers for Disease Control and Prevention and the National Down Syndrome Society. Am J Med Genet A 146A:2998-3010.

Sherman SL, Allen EG, Bean LH, Freeman SB. 2007. Epidemiology of Down syndrome. Ment Retard Dev Disabil Res Rev 13:221-227.

Siperstein GN, Norris J, Corbin S, Shriver T. 2003. Multinational study of attitudes toward individuals with intellectual disabilities: General findings and calls to action. Special Olympics. Website: http://www. sustainable-design.ie/arch/2003_Special_Olympics-multinational_study. pdf.

Smith P. 2007. Have we made any progress? Including students with intellectual disabilities in regular education classrooms. Intellect Dev Disabil 45:297-309.

Tamm M, Prellwitz M. 2001. If I had a friend in a wheelchair: Children's thoughts on disabilities. Child Care Health Dev 27:223-240.

Townsend MA, Wilton KM, Vakilirad T. 1993. Children's attitudes toward peers with intellectual disability. Am J Intellect Dev Disabil 37:405-411.

Tripp A, French R, Sherrill C. 1995. Contact theory and attitudes of children in physical education programs toward peers with disabilities. Adapt Phys Act Q 12:524-532.

Unger D. 2002. Employers' attitudes toward persons with disabilities in the workforce: Myths or realities? Focus Autism Other Dev Disabil 17:2-10.

Yang Q, Rasmussen SA, Friedman JM. 2002. Mortality associated with Down's syndrome in the USA from 1983 to 1997: A population-based study. Lancet 359:1019-1025. 